\title{
Geology, Construction Materials and Building Phases of the El Gustal Neolithic Menhir (Álava, Spain)
}

\author{
Luis M. Martínez-Torres*
}

Departamento de Geodinámica, University of the Basque Country UPV-EHU, Spain

\begin{abstract}
The Neolithic menhir El Gustal is located on a karstificated Coniacian limestone. The original morphology of the monolith and the pit has been preserved, and fragments of limestone filled the hollow. This has made it possible to identify construction phases of the most elementary stone constructive typology. Firstly, the original position of the monolith in the quarry of origin has been determined. Secondly, according to the basic laws of the lever, the forces required to erect the monolith provided by three movements employing two class I and one class II levers have been determined. Thirdly, the fall and subsequent breakage of the menhir due to the shallowness of the pit has been deduced.
\end{abstract}

Keywords: Backfill, Collapse, Lever, Limestone, Monolith, Pit, Stability.

\section{INTRODUCTION}

Independently of its sculptural, monumental or functional character, the menhir is the simplest of stone constructions. Structurally, it consists of a monolith, a pit and backfill for the pit. The preservation of the original morphology of these three elements at the El Gustal menhir makes it possible to deduce the whole construction process, from quarrying to its collapse. Furthermore, to erect a monolith the minimum force required can be calculated by a lever construction model.

The El Gustal menhir is located in the Valderejo Natural Park in the province of Álava, Autonomous Community of the Basque Country, northern Spain $\left(42^{\circ} 54.127\right.$ 'N, $3^{\circ}$ 14.642' W, $1204 \mathrm{~m}$ ) (Fig. 1). It was discovered in 1982 by Murga [1] and excavated by Lobo [2]. In the close vicinity there is a flint workshop from which several hundred stone artefacts have been collected with typologies having their origin in the late Middle and early Upper Palaeolithic [3], while taking into account the period of the numerous megaliths present in the region, the age of the menhir most likely falls in the Neolithic era [1].

Geologically, El Gustal is situated on the Álava Block, southern unit of the Basque-Cantabrian Basin, at the western termination of the Pyrenees. Structurally, menhir is located in the hinge of the Sobrón-Valderejo anticline on Coniacian biosparite locally known as Subijana Limestone. The poorly stratified limestone has a horizontal position. Morphologically, the menhir is located on the slope of a reverse structural relief, $3 \mathrm{~m}$ from the vertical ramp or slope of the karst (Fig. 1). This proximity to the escarpment and relative altitude provides a high degree of visibility.

*Address correspondence to this author at the Departamento de Geodinámica, University of the Basque Country UPV-EHU, Apdo. 644, E48080 Bilbao, Spain; Tel: +34-946012557; Fax: +34-946013500;

E-mail: luismiguel.martinez@ehu.es
The menhir, which was found to be broken into two fragments, was rejoined during restoration with the help of three corrugated galvanized iron rods. The dimensions of the menhir are: $348 \mathrm{~cm}$ high, an average width of $60 \mathrm{~cm}$ and an average depth of $20 \mathrm{~cm}$. With these dimensions the monolith can be defined morphologically as a laminate. The top is carved suggesting an anthropomorphic silhouette (Fig. 1).

The archaeological excavation has exposed the original pit carved into the limestone pavement [2]. The observation of the hollow increased the understanding of the construction process, giving added value to the monument. For this reason, it was decided to leave it exposed and move the menhir $2 \mathrm{~m}$ toward the steep slope, gaining visibility and monumentality.

\section{THE MONOLITH}

The menhir weighing $1058 \mathrm{~kg}$ is a single piece of Coniacian biosparite limestone from the immediate surroundings. The monolith, with its given dimensions of $348 \times 60 \times 20$ $\mathrm{cm}$, was aligned with the long axis in the vertical, the intermediate axis in the East-West direction and the short axis in the North-South direction (Fig. 1). Analysis of a very similar limestone gave average values of a density of $2.6 \mathrm{~g} / \mathrm{cm}^{3}$, a porosity of only $0.5 \%$, a break resistance of $1110 \mathrm{~kg} / \mathrm{cm}^{2}$ and great durability to alteration [4]. To calculate the weight of a given monolith section both the surface of that section to a constant thickness of $20 \mathrm{~cm}$ and its density are considered.

The approximate E-W orientation of the menhir's centre axis, as observed in the excavated pit, is parallel to a set of joints $\mathrm{J} 2$ orientation N80E-N100W (Fig. 1). In the substrate another set of vertical joints is also visible, J1 with an $\mathrm{N}-\mathrm{S}$ orientation. This system of joints, which determined the excavation of the pit, is also reflected in the morphology of the monolith. The long axis of the menhir is parallel to the $\mathrm{J} 2$ set and the centre axis to the $\mathrm{J} 1$ set (Fig. 1). The intersection of the planes $\mathrm{J} 1$ and $\mathrm{J} 2$ corresponds to the base or minor axis of the monolith. 


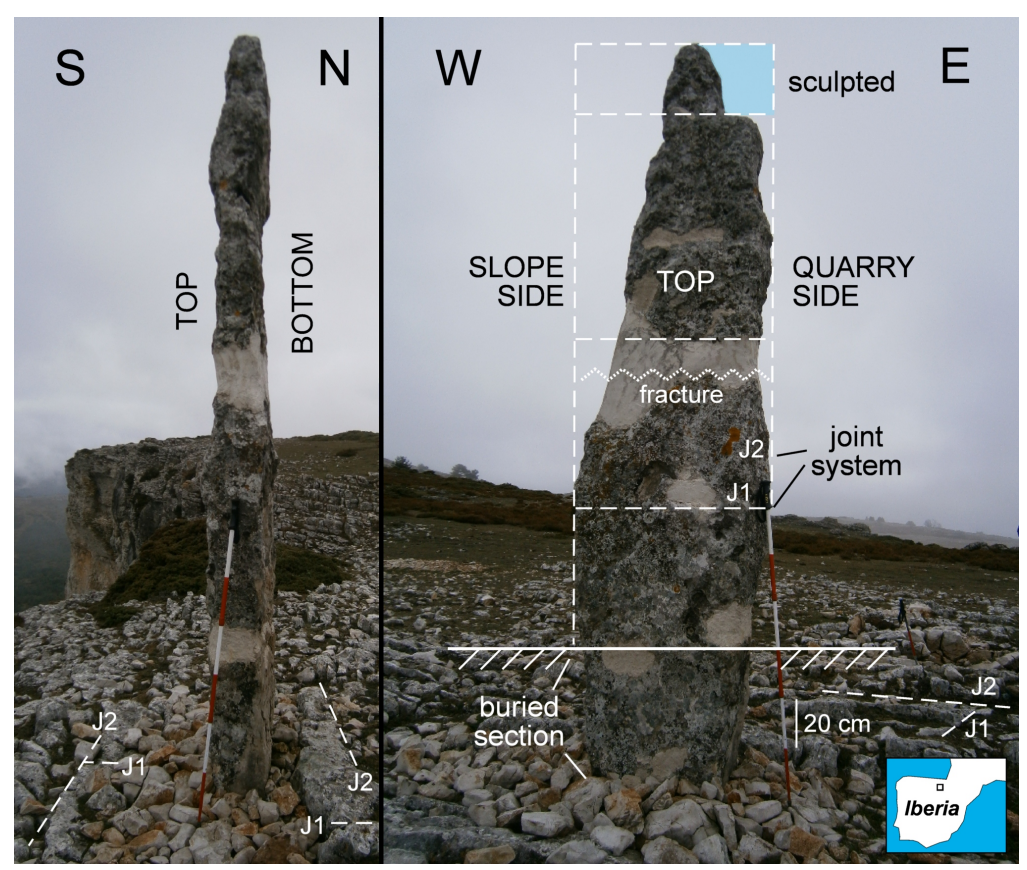

Fig. (1). El Gustal Menhir. Left: East profile. Right: South profile.

The plane of the monolith directed towards $\mathrm{S}$ shows intense karstification processes identical to those observed in the limestone of the environment. The parallel plane oriented $\mathrm{N}$ is a flat surface without erosive morphologies. Therefore, the $\mathrm{S}$ and $\mathrm{N}$ planes correspond respectively to the top and wall of the same layer (Fig. 1).

The narrow surface facing towards the $\mathrm{W}$ has a concentric shape with rounded forms. In contrast, the surface facing $E$ is rectilinear with acute edges and a profile that would suggest conchoidal fractures probably caused by mechanical impact. Given this morphology it can be ascertained that the $\mathrm{W}$ face was originally exposed and that the $\mathrm{E}$ face would be the plane hewn from the quarry (Fig. 1). Taken into account the typologies of old quarries described for limestone with structural relief, it is speculated that origin of the monolith would have been from a dip-slope quarry [5].

The nearest outcrops of limestone, from which the monolith could potentially be extracted, are located between 50 and $200 \mathrm{~m}$, however, it has not been possible to pinpoint the original quarry hole. In any case, the levels from where it could have been hewn are at heights that are similar or slightly greater than the height of the menhir, which implies that the monolith was either moved horizontally or lowered. This observation has already been demonstrated in other megaliths and even in later historical buildings [6].

\section{THE PIT AND ITS BACKFILL}

The pit is very well defined because the limestone that was cleared from the limestone pavement conserved the original workings (Fig. 2). Horizontally, the pit has a quadrangular shape with sides oriented along the sets of vertical joints N080E and their orthogonal N170E. The width of the pit in the E-W direction is $60-80 \mathrm{~cm}$, consistent with the 60 $\mathrm{cm}$ width for the base measurement of the monolith. In the $\mathrm{N}-\mathrm{S}$ direction, the base of the pit measured $2 \mathrm{~m}$. The maxi- mum depth of the pit is $60 \mathrm{~cm}$, which was also the maximum depth of the monolith buried (Fig. 1).

The most interesting morphological feature of the pit can be observed on its N-S profile (Fig. 2). There is a gentle slope of $1 \mathrm{~m}$ in length at $10^{\circ}$ in the northernmost part where the pit starts. The intermediate section of the slope which is $35^{\circ}$ is measured $80 \mathrm{~cm}$. The base of the pit is horizontal and measured $40 \mathrm{~cm}$ in profile. The profile of the pit ended up in a vertical plane which is $60 \mathrm{~cm}$ in height (Fig. 3b).

In the vertical plane of the pit conchoidal fractures through mechanical impact can be observed, which were probably made with stone mallets. In any case, the excavation of the pit did not require much work given that the surface layers of the limestone pavement are broken into decimetric blocks that, for the most part, do not require any additional fracturing for removal. Natural and artificial limestone fragments from the excavation work of the pit were later used as backfill for the pit in order to hold the monolith in place.

\section{CONSTRUCTION PHASE}

The morphology of the monolith, pit and backfill fragments has made it possible to identify the construction phases of the El Gustal menhir. Those phases where it was possible, forces and resistances were calculated according to the law of the lever, solved geometrically by Archimedes. Mathematically, the law of the lever is expressed by $F_{\text {in }} d_{\text {in }}=$ $F_{\text {out }} d_{\text {out }}$, where $F_{\text {in }}$ is the input force or effort and $F_{\text {out }}$ is the output force or resistance. The distances $d_{\text {in }}$ and $d_{\text {out }}$ are the perpendicular distances between the forces and the fulcrum. Levers are classified into three classes by the relative positions of the fulcrum, the effort and the resistance.

\section{Quarrying, Carving and Transportation of the Monolith}

The $\mathrm{S}$ and $\mathrm{W}$ faces, corresponding to the top of the layer and the slope of the terrain, were exposed (Fig. 1). The $\mathrm{N}$ 


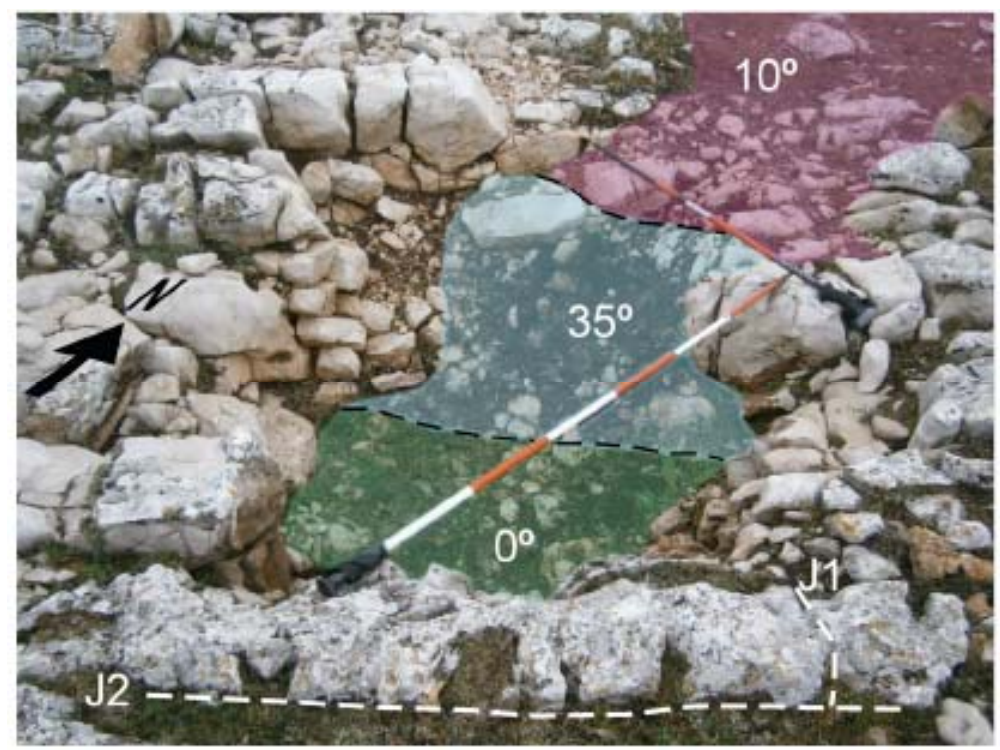

Fig. (2). Oblique view from the south of the excavated pit, indicating the three ramps.

face of the monolith, which is the wall of the layer, lay flat on the lower layer. The $\mathrm{E}$ face of the monolith was attached to the quarry. The wall of the stratum was used in order to separate the monolith from the rock mass and mechanically breaking off the $\mathrm{E}$ face of the erected monolith. Some of the conchoidal fractures on this E face might have arisen due to the quarrying of the monolith.

The morphology of the monolith allows it to be positioned according to the joint sets of the substrate (Fig. 2). Joint set $\mathrm{J} 2$ is oriented approximately E-W on the ground and $\mathrm{N}-\mathrm{S}$ on the monolith before it erection. Thus, it follows that the piece had to be rotated $90^{\circ}$ clockwise from the quarry to the placement hole (Fig. 3a).

\section{Excavation of the Pit}

It has already been indicated above that conchoidal fractures produced by mechanical impact can be seen on one side of the pit. As it is quite often the case, the same tools that were employed in the extraction and carving of the monolith, were probably used to excavate the pit (Fig. 3b). One possible instrument could be mallets, which is made from ophite (dolerite), which has already been described in Álava [7]. In any case, the limestone substrate is fractured and is relatively easy to excavate.

The natural and artificial fragments from the pit are usually used as a support during the erection of the monolith and especially for the backfilling of the hollow.

\section{First Class I Lever}

When the centre of gravity of the monolith is placed on the intersection of the horizontal ground surface with the $10^{\circ}$ ramp, the first class I lever intervenes (Fig. 3c). The beginning of the ramp acts as a fulcrum F1. When the monolith is moved progressively over F1 various loads allow the monolith to swing until it rests on the $10^{\circ} \mathrm{ramp}$ (Fig. 3d). The first lever acts in a passive mode, given that apart from dragging the monolith no external force is required to tilt the monolith.

\section{Second Class I Lever}

In this phase, the fulcrum $\mathrm{F} 2$ is at the intersection of the $10^{\circ}$ and $35^{\circ}$ ramps. The lever initially acts with the monolith inclined at $10^{\circ}$ (Fig. 3e) and finishes at $35^{\circ}$ (Fig. 3f). This requires an initial vertical load of $349 \mathrm{~kg}$, decreasing progressively, as per the cosine of the angle of inclination, down to $290 \mathrm{~kg}$. With only $59 \mathrm{~kg}$ difference the monolith is raised to $25^{\circ}$.

\section{Class II lever and filling of the pit}

The monolith was rested on both the $35^{\circ}$ ramp as well as on the limestone fragments, which had to be placed at least up to the centre of gravity of the monolith (Fig. 3g). In this position the minimum initial vertical force required to begin the erection of the monolith was $857 \mathrm{~kg}$. This force decreased progressively, as per the cosine of the angle of inclination of the monolith, until it was placed in the upright position, where the force was zero (Fig. 3h). The class II lever has the fulcrum (F3) at the intersection of the $35^{\circ}$ ramp with the horizontal surface of the pit. Afterwards, the pit was filled with fragments of limestone.

\section{Fall and Breakage}

The now erected monolith is exposed to external pushing and vibrations, especially from the wind. Winds of 120 $\mathrm{km} / \mathrm{h}$, representing a pressure of $80 \mathrm{~kg} \cdot \mathrm{m}^{2}$, produces a moment of $264 \mathrm{~kg} \cdot \mathrm{m}$. The buried section of the monolith has a moment of just $32 \mathrm{~kg} \cdot \mathrm{m}$ (Fig. 3h) which would explain why it collapsed (Fig. 3i). The position of the moor where the menhir stands is exposed to all winds, which are often exceeding the stated speed. From a constructive standpoint and in terms of stability, the erected monolith has a safety factor of only $0.78 \%$. For a safety factor $\mathrm{SF}=1$ the monolith should be buried at least $87 \mathrm{~cm}$, i.e., $27 \mathrm{~cm}$ more than the $60 \mathrm{~cm}$ at which it is buried now. In civil engineering, in order to construct this kind of structure a safety factor SF $=3$ is recommended. All these calculations are based on European standardization [8]. 

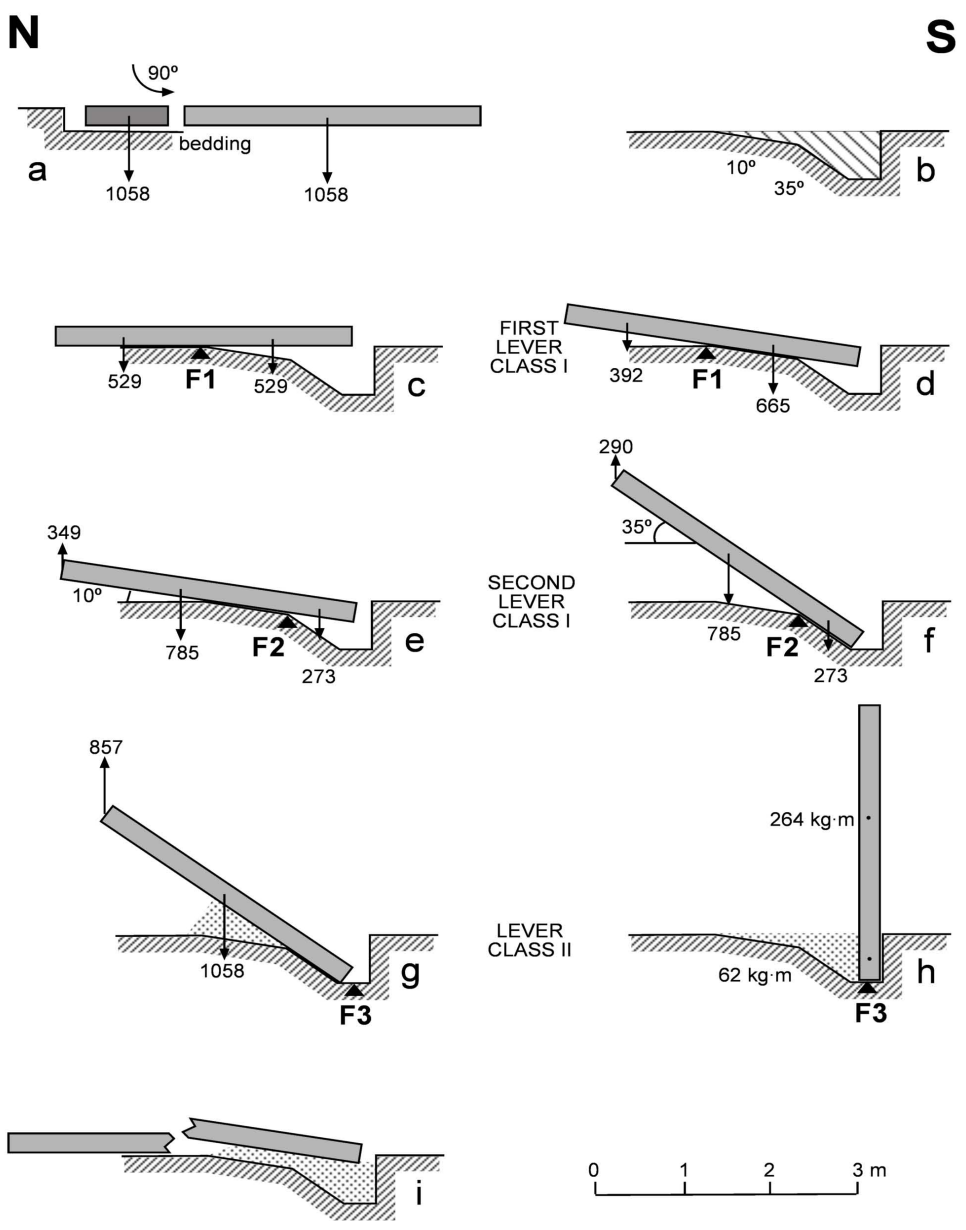

Fig. (3). Construction phases of the El Gustal menhir. Forces given in kg.

The fall caused the monolith to break along a surface sub-parallel to the set of joints J1 (Fig. 1).

\section{CONCLUSIONS}

The El Gustal menhir and the morphology of the three elements, the monolith, the pit and the filling for the pit, make it possible to reconstruct the construction phases as well as to calculate the minimum forces required for the erection of the monument.

The monolith was transported to the pit on the lower flat surface, corresponding to the wall of the stratum. Before beginning to erect it, the monolith was horizontally rotated at $90^{\circ}$ clockwise (Fig. 3a).

The pit has a N-S profile with a $10^{\circ}$ northern ramp, another at $35^{\circ}$, a horizontal base and a vertical southern end around $60 \mathrm{~cm}$ in height (Fig. 3b). The monolith was gradually moved and supported on these ramps.

The method of mechanical erection can be explained by using two class I levers and a final class II lever. The first class I lever is passive, i.e., it does not require the application of any external force, exploiting the movement of the monolith onto the fulcrum F1 (Figs. 3c and 3d). The second lever, also class I, with a fulcrum F2 at the intersection of the $10^{\circ}$ and $35^{\circ}$ ramps, starts with a minimum vertical force of 349 $\mathrm{kg}$, ending up with a force of $290 \mathrm{~kg}$ (Figs. 3f and 3g). The third and final lever, in this case class II, requires a minimum vertical load of $857 \mathrm{~kg}$ to place the monolith upright (Figs. $\mathbf{3 g}$ and 3h). When erected, the pit was filled with fragments of limestone that were produced while digging out the pit.

The last distinct phase was its fall and consequent breakage (Fig. 3i). The volume of the monolith inserted into the pit produced moments with very low values as compared to the exposed section of the monolith, such that any external disturbance could cause it to collapse.

\section{CONFLICT OF INTEREST}

The author confirm that this article content has no conflicts of interest.

\section{ACKNOWLEDGEMENTS}

The restoration and repositioning of the El Gustal menhir was funded by the Provincial Council of Álava, through the department of Culture and Environment, and the Valderejo Natural Park.

\section{REFERENCES}

[1] Instituto Alavés de Arqueología, Carta Arqueológica de Álava, Vitoria-Gasteiz: Diputación Foral de Álava, 1987.

[2] P. Lobo, "Menhir del Portillo del Gustal (Lahoz)", Arkeioikuska: investigación arqueológica 2007, pp. 125-130, 2007. 
[3] J. Fernández-Areso, and J. A. Sáenz-de-Buruaga, "Nota preliminar sobre el conjunto industrial de superficie del Gustal (Valle de Valderejo, Álava)", Estudios de Arqueología Alavesa, vol. 23, pp. 16, 2006.

[4] L. M. Martínez-Torres, "Cartografía litológica y procedencia de las rocas empleadas en la construcción", in A. Azkarate et al., Eds., Catedral de Santa María. Vitoria-Gasteiz. Plan Director de Restauración, Diputación Foral de Alava y Fundación Catedral Santa María: Vitoria-Gasteiz, vol. 1, pp. 232-241, 1999.

[5] L. M. Martínez-Torres, "The Typology of Ancient Quarries within the Paleocene Limestone of Álava in Northern Spain", Geoarcheology, vol. 24, pp.42-58, 2009.
[6] L. M. Martínez-Torres, "Lithological maps of churches in the Diocese of Vitoria (Spain): Space-time distribution of building stones and ancient quarries", Building and Environtment, vol. 42, pp. 860$865,2007$.

[7] A. Tarriño, "Indicios de minería de sílex en Treviño (sur de la Cuenca Vasco-Cantábrica)", in M. Santonja et al., Eds., Geoarqueología y Patrimonio en la Península Ibérica y el entorno mediterráneo, ADEMA: Soria, pp. 439-659, 2005.

[8] European Committe for Standardisation, Eurocode 1(EN 1991): Actions on structures, Brussels: CEN, 2003.

(C) Luis M. Martínez-Torres; Licensee Bentham Open.

This is an open access article licensed under the terms of the Creative Commons Attribution Non-Commercial License (http://creativecommons.org/licenses/by-nc/3.0/) which permits unrestricted, non-commercial use, distribution and reproduction in any medium, provided the work is properly cited. 